\title{
Treatment of Severe Cold Contact Urticaria with Omalizumab: Case Reports
}

\author{
Petra Brodská Peter Schmid-Grendelmeier \\ Allergy Unit, Department of Dermatology, Zurich University Hospital, \\ Zurich, Switzerland
}

\section{Key Words}

Anti-immunoglobulin E · Cold contact urticaria $\cdot$ Omalizumab $\cdot$ Physical urticaria

\begin{abstract}
We report 2 patients with cold urticaria with different response to treatment with omalizumab (Xolair ${ }^{\circledast}$ ). Cold contact urticaria (CCU) is a common subtype of physical urticaria. It is characterized by the development of wheal and/or angioedema within minutes after cold contact. Clinical manifestation of CCU can range from mild, localized whealing to lifethreatening anaphylactic shock reactions. Omalizumab has been described to be useful in cases of chronic urticaria and may be an interesting option for treatment of CCU. We describe one patient with significant and long-lasting improvement of symptoms and one without any improvement after anti-immunoglobulin E therapy. In our case reports, we want to highlight that there is still a small group of patients without benefit from omalizumab treatment. It is necessary to identify this minor subgroup of patients where omalizumab does not represent an effective treatment possibility.
\end{abstract}

\section{Introduction}

Cold contact urticaria (CCU) accounts for approximately $3 \%$ of all cases of chronic urticaria [1]. Among all physical urticarias, CCU represents the second most common subtype after symptomatic dermographism [2]. CCU is characterized by development of wheal and/or angioedema within minutes after cold contact. CCU patients are also at risk of anaphylaxis or oropharyngeal edema. Acquired CCU is mostly idiopathic or can be secondary in cryoglobulinemia, infectious diseases, etc.

Current guidelines for the symptomatic treatment of CCU recommend a stepwise approach beginning with the classical dose of nonsedating $\mathrm{H}_{1}$-antihistamines (nsAHs), then increasing the doses of nsAHs up to 4-fold if symptoms persist before changing to a different nsAHs. In very severe cases also other therapeutic options such as 
cyclosporin A or oral steroids might be used [3]. The goal of the treatment of urticaria is determined by complete symptom control. It has been previously shown that omalizumab treatment can be safe and effective in patients suffering from recalcitrant physical urticarias such as cold urticaria [4].

\section{Case Reports}

We report different effects of anti-immunoglobulin E (IgE) therapy in 2 patients with cold contact urticaria, both nonresponsive to high doses of nsAHs.

First Case Report

A 53-year-old woman suffered from severe, treatment-refractory cold contact urticaria. Before anti-IgE treatment, the patient had been affected by recurrent itchy and painful rash in the face and other cold-exposed areas for 4 months. Raised, erythematous, intensely pruritic skin lesions typically developed within minutes after exposure to low temperatures, especially after contact with cold air or cool water. She did not tolerate ingestion of cold drinks and foods; she experienced itching of the lips and tongue. There were no associated symptoms, such as fever or arthralgia. Progressing symptoms limited her outdoor activities in the cold and also food choices. She has received several unsuccessful therapies, including various sedating and nonsedating antihistamines, and intermittent oral steroid treatments. Before anti-IgE treatment, cold provocation test was performed. An ice cube applied to the skin resulted in the development of massive wheal and redness within 3 min after removal. Her medical history included chronic hepatitis B. Hepatitis serological marker (anti-HBs) was positive. Furthermore, she had undergone surgery for urothelial cell carcinoma 6 years previously, and was currently without any urological problems. Other relevant concomitant diseases were excluded. No family members had cold-induced rashes. Before anti-IgE therapy was initiated, hte patient's total IgE was $207 \mathrm{kU} / \mathrm{l}$. The patient received a subcutaneous dose of $300 \mathrm{mg} / \mathrm{month}$ of omalizumab (added to a stable dose of $\mathrm{H}_{1}$-antihistamine). Omalizumab was administered according to the US Food and Drug Administration-approved dosing table for the treatment of asthmatic patients, determining the omalizumab dose by body weight and total IgE levels [5]. The patient reported significant improvement of symptoms already within 1 week after the first injection. Omalizumab was well tolerated, without any adverse effects. After 4 months with complete symptom control, anti-IgE therapy was stopped. At the last follow-up, 5 months after the last application of omalizumab, the patient is currently still free of symptoms. Cold provocation test did not lead to any development of urticarial rash. In case of recurrence of urticaria symptoms, we plan to restart anti-IgE therapy.

\section{Second Case Report}

A 30-year-old woman presented with severe cold intolerance with urticarial rash for 1 year. Symptoms were induced also by cold provocation test. Cold exposure was extremely disabling for her. The patient experienced diffuse urticaria with shortness of breath and dizziness occasionally. No evidence for an underlying disease (e.g. infection, cryoglobulinemia) was found. Her personal and family history was negative. Before anti-IgE therapy was initiated, the patient's total IgE was 20.8 $\mathrm{kU} / \mathrm{l}$. The patient did not respond to oral antihistamine treatment including 4 -fold dosage. Therefore treatment with $300 \mathrm{mg}$ omalizumab subcutaneously every 4 weeks was initiated. The patient repeatedly reported fatigue and somnolence all day long after administration of omalizumab. Unfortunately, anti-IgE therapy resulted in only incomplete symptom control. Due to adverse events and insufficient efficacy, omalizumab treatment was discontinued after 8 months. Cyclosporin A treatment was initiated with $200 \mathrm{mg}$ daily, combined with $\mathrm{H}_{1}$-antihistamine. Due to headaches reported by the patient, the dosage of cyclosporin A was reduced to $150 \mathrm{mg}$ daily. At the last followup, the patient still has not achieved complete remission. The patient has also received an emergency kit with oral corticosteroid, antihistamine and an adrenaline injector.

\section{Discussion}

Cold contact urticaria accounts for approximately 3\% of all cases of chronic urticaria [1]. Among all physical urticarias, CCU represents the second most common subtype 
after symptomatic dermographism [2]. CCU is characterized by the development of wheal and/or angioedema within minutes after cold contact. Extensive cold contact of large areas of skin may lead to systemic reactions such as generalized urticaria, dyspnoea, tachycardia, hypotension and loss of consciousness [6]. Severe CCU has a significant impact on the patient's quality of life both in a physical and psychological sense [7].

The onset of CCU symptoms may occur at any age but shows a peak in young adults and a weak predominance in women [6]. The symptoms of all physical urticarias are caused by the activation of mast cells and by their release of proinflammatory mediators. However, it is largely unknown how and why mast cells are activated in physical urticaria, i.e. which signals are responsible for mast cells activation [8]. Although no underlying causes are detectable in most CCU patients, an association of CCU with cryoglobulinemia, hematologic disorders has been described in a small subset of patients [9]. Also, a link between CCU and various viral, parasitic, or bacterial infections could be observed. Genomic deletions in PLCG2 were recently found in 3 independent families with lifelong cold urticaria [10]. Wanderer et al. [6] proposed a classification scheme for cold urticaria based on the severity of reactions (table 1).

It is important to note that anaphylactic reactions are very common in patients with cold urticaria. These occur most often during water immersion [11]. Patients who experience oropharyngeal reactions to cool liquids or foods (most commonly manifested as lip swelling) are said to be more likely to experience systemic reactions [4].

CCU must be distinguished from a cold-induced form of cholinergic urticaria [12]. This disorder should be suspected in individuals who have typical multiple small urticarial lesions only when exercising in the cold. Cold-induced cholinergic urticaria is not associated with positive cold provocation test [4]. In a small percentage of cases, cold urticaria is associated with the presence of a range of serum cryoproteins. The presence of a cryoprotein can reflect an underlying diagnosis of essential mixed cryoglobulinemia, hepatitis, autoimmune disease, or lymphoma [4]. Cryoproteins were identified in fewer than $10 \%$ of adults in a large series [11].

Avoidance of critical cold exposure should be recommended [3] but is often impossible. Symptomatic treatment of choice is the use of nsAHs [3]. In patients with severe CCU who continue to experience symptoms despite up-dosing of nsAHs, the concomitant use of leukotriene receptor antagonists or $\mathrm{H}_{2}$ blockers has been described [13]. Also the successful use of cyclosporin A and anti-IgE therapy in CCU has been reported $[4,14]$. Patients with a history of anaphylaxis or systemic symptoms should receive an emergency kit containing an adrenaline injector, oral corticosteroid and antihistamine [11].

Omalizumab is a recombinant humanized monoclonal antibody against IgE. It is approved for the treatment of moderate-to-severe persistent asthma in patients with a positive skin test response or in vitro reactivity to a perennial aeroallergen and symptoms that are inadequately controlled with inhaled corticosteroids (in the Unites States) or inhaled corticosteroids plus a long-acting inhaled $\beta_{2}$-agonist (in Europe) [5]. Omalizumab blocks the binding of IgE to the FceRI receptor on the surface of target cells, including mast cells and basophils, thus reducing receptor expression and the 
release of inflammatory mediators [15]. Four proof-of-concept trials investigated omalizumab in patients with chronic spontaneous urticaria who remained symptomatic despite antihistamine therapy [16-19]. It is known that approximately $30 \%$ to $50 \%$ of patients with chronic idiopathic urticaria produce IgG autoantibodies against either IgE or its high-affinity receptor (FceRI) [20]. A subgroup of patients with chronic spontaneous urticaria exhibits IgE antibodies directed against autoantigens, such as thyroperoxidase [19]. All four studies showed that omalizumab significantly improved urticaria activity scores with rapid onset of effect which persisted for the duration of treatment [16-19]. A dose-finding study has demonstrated that $300 \mathrm{mg}$ omalizumab are as efficient as $600 \mathrm{mg}$ and superior to $75 \mathrm{mg}$ [16]. Currently large multi-center phase III studies are ongoing to investigate the efficacy and safety of omalizumab in CIU (ClinicalTrials.gov identifier: NCT01292473).

It has been previously shown that omalizumab treatment can be safe and effective in patients suffering from recalcitrant physical urticaria such as cold contact urticaria [4]. Also other cases of successful use of omalizumab in physical urticaria such as solar urticaria [21] and pressure urticaria [22] have been described. In table 2 we summarize those patients with cold contact urticaria treated with omalizumab.

According to the summary of omalizumab product characteristics, the most commonly observed adverse reactions are injection site reactions, headache, pyrexia and upper abdominal pain [5]. Most of the reactions are mild or moderate in severity and quite rare (about 7\%) [23]. Fatigue described by our patient is defined as uncommon adverse event $(\geq 1 / 1,000$ to $<1 / 100)$ [5]. In general, however, omalizumab is well tolerated as has been learned from the use of omalizumab in large cohorts of adult patients [23] and children [24] suffering from allergic asthma.

Up until now, no clear indications on possible responders of CCU patients with omalizumab or useful dosage and length of therapy can be given. From our 2 patients case 1 was responding very fast (within 1 week) and had a long-lasting improvement. On the other hand case 2 did not respond in a satisfactory manner and also suffered from a variety of side effects. However, it has to be considered that this patient also did not respond very well to cyclosporin A and also suffered from a broader spectrum of side effects with this drug.

\section{Conclusions}

Many case reports have already shown the beneficial effect of omalizumab in patients with recalcitrant physical urticaria [4, 21, 22, 25]. In addition to previously published reports, our case suggests that omalizumab may be an effective, rapid and safe treatment option in patients with cold contact urticaria who do not sufficiently respond to standard therapy as recommended by existing guidelines. Still there is a small group of patients without sufficient response to omalizumab. Further research is necessary to clarify the mechanism of action of omalizumab in patients with CCU. Future trials, including longer durations of treatment, should fully evaluate the potential of this agent in the treatment of all recalcitrant physical urticarias. Another focus of interest will be to identify the patients who will not profit from omalizumab treatment [8]. 


\section{Sources of Support}

Petra Brodská is a recipient of an EAACI research award for junior members.

Table 1. Classification scheme for cold contact urticaria [6]

Severity of reactions

Cold urticaria type 1 reactions confined to the area of skin that came into contact with the cold

type 2 generalized urticaria not associated with cardiovascular or respiratory symptoms

type 3 generalized urticaria associated with cardiovascular or respiratory symptoms

Table 2. Characteristics of cold contact urticaria patients treated with omalizumab

\begin{tabular}{|c|c|c|c|c|c|c|c|}
\hline $\begin{array}{l}\text { Pa- } \\
\text { tient }\end{array}$ & First author, year & Sex & $\begin{array}{l}\text { Age } \\
\text { years }\end{array}$ & $\begin{array}{l}\text { Duration } \\
\text { of CCU }\end{array}$ & Previous medication & $\begin{array}{l}\text { Omalizumab } \\
\text { dosage }\end{array}$ & $\begin{array}{l}\text { Successful } \\
\text { use }\end{array}$ \\
\hline 1 & Boyce [4], 2006 & woman & 12 & 2 years & high-dose nsAH, montelukast & $\begin{array}{l}375 \mathrm{mg} / \\
2 \text { weeks }\end{array}$ & yes \\
\hline 2 & Metz [8], 2011 & man & 19 & NA & high-dose nsAH & $\begin{array}{l}150 \mathrm{mg} / \\
4 \text { weeks }\end{array}$ & yes \\
\hline 3 & our patient - case 1,2012 & woman & 53 & 4 months & $\begin{array}{l}\text { high-dose nsAH, occasional oral } \\
\text { steroids }\end{array}$ & $\begin{array}{l}300 \mathrm{mg} / \\
4 \text { weeks }\end{array}$ & yes \\
\hline 4 & our patient - case 2,2012 & woman & 30 & 1 year & high-dose nsAH & $\begin{array}{l}300 \mathrm{mg} / \\
4 \text { weeks }\end{array}$ & no \\
\hline
\end{tabular}

\section{References}

1 Buss YL, Sticherling M: Cold urticaria; disease course and outcome - an investigation of 85 patients before and after therapy. Br J Dermatol 2005;153:440-441.

-2 Siebenhaar F, Weller K, Mlynek A, et al: Acquired cold urticaria: clinical picture and update on diagnosis and treatment. Clin Exp Dermatol 2007;32:241-245.

-3 Zuberbier T, Asero R, Bindslev-Jensen C, Walter CG, Church MK, Gimenez-Arnau AM, et al: EAACI/GA(2)LEN/EDF/WAO guideline: management of urticaria. Allergy 2009;64:1427-1443.

4 Boyce JA: Successful treatment of cold-induced urticaria/anaphylaxis with anti-IgE. J Allergy Clin Immunol 2006;117:1415-1418.

5 Xolair: summary of product characteristics. European Medicines Agency; 2010. Available at: http://www.ema.europa.eu/docs/en_GB/document_library/EPAR_-_Product_Information/human/ 000606/WC500057298.pdf.

6 Wanderer AA, Grandel KE, Wasserman SI, Farr RS: Clinical characteristics of cold-induced systemic reactions in acquired cold urticaria syndromes: recommendations for prevention of this complication and a proposal for a diagnostic classification of cold urticaria. J Allergy Clin Immunol 1986;78:417-423.

7 O'Donell BF, Lawlor F, Simpson J, Morgan M, Greaves MW: The impact of chronic urticaria on the quality of life. Br J Dermatol 1997;136:197-201. 
8 Metz M, Altrichter S, Ardelean E, Kessler B, Krause K, Magerl M, Siebenhaar F, Weller K, Zuberbier T, Maurer M: Anti-Immunoglobulin-E treatment of patients with recalcitrant physical urticaria. Int Arch Allergy Immunol 2011;154:177-180.

-9 Doeglas HM, Rijnten WJ, Schroder FP, Schirm J: Cold urticaria and virus infection: a clinical and serological study in 39 patients. Br J Dermatol 1986;114:311-318.

10 Ombrello MJ, Remmers EF, Sun G, Freeman AF, Datta S, Torabi-Parizi P, et al: Cold urticaria, immunodeficiency, and autoimmunity related to PLCG2 deletions. N Engl J Med 2012;366:330-338.

-11 Krause K, Zuberbier T, Maurer M: Modern approaches to the diagnosis and treatment of cold contact urticaria. Curr Allergy Asthma Rep 2010;10:243-249.

12 Kaplan AP, Garofalo J: Identification of a new physically-induced urticaria: cold induced cholinergic urticaria. J Allergy Clin Immunol 1981;68:438-441.

13 Bonadonna P, Lombardi C, Senna G, et al: Treatment of acquired cold urticaria with cetirizine and zafirlukast in combination. J Am Acad Dermatol 2003;49:714-716.

14 Marsland AM, Beck MH: Cold urticaria responding to systemic ciclosporin. Br J Dermatol 2003;149:214 215.

-15 Oliver JM, Tarleton CA, Gilmartin L, Archibeque T, Qualls CR, Diehl L, et al: Reduced FcepsilonRImediated release of asthma-promoting cytokines and chemokines from human basophils during omalizumab therapy. Int Arch Allergy Immunol 2009;151:275-284.

-16 Saini S, Rosen KE, Hsieh HJ, Wong DA, Conner E, Kaplan A, Spector S, Maurer M: A randomized, placebocontrolled, dose-ranging study of single-dose omalizumab in patients with $\mathrm{H}_{1}$-antihistamine-refractory chronic idiopathic urticaria. J Allergy Clin Immunol 2011;128:567-573.

17 Kaplan AP, Joseph K, Maykut RJ, Geba GP, Zeldin RK: Treatment of chronic autoimmune urticaria with omalizumab. J Allergy Clin Immunol 2008;122:569-573.

18 Gober JM, Sterba PM, Eckman JA, Saini SS: Effect of Anti-IgE (omalizumab) in chronic idiopathic urticaria (CIU) patients. J Allergy Clin Immunol 2008;121(suppl):S147.

19 Maurer M: Efficacy and safety of omalizumab in patients with chronic urticaria who exhibit IgE against thyroperoxidase. J Allergy Clin Immunol 2011;128:202-209.

-20 Sabroe RA, Fiebiger E, Francis DM, Mauer D, Seed PT, Grattan CE, et al: Classification of anti-FcepsilonRI and anti-IgE autoantibodies in chronic idiopathic urticaria and correlation with disease severity. Allergy Clin Immunol 2002;110:492-499.

-21 Güzelbey 0, Ardelean E, Magerl M, Zuberbier T, Maurer M, Metz M: Successful treatment of solar urticaria with anti-immunoglobulin E therapy. Allergy 2008;63:1563-1565.

22 Bindslev-Jensen C, Skov PS: Efficacy of omalizumab in delayed pressure urticaria: a case report. Allergy 2010;65:138-139.

23 Korn S, Thielen A, Seyfried S, et al: Omalizumab in patients with severe persistent allergic asthma in a real-life setting in Germany. Respir Med 2009;103:1725-1731.

-24 Busse WW, Morgan WJ, Gergen PJ, Mitchell HE, Gern JE, Liu AH, Gruchalla RS, Kattan M, Teach SJ, Pongracic JA, Chmiel JF, Steinbach SF, Calatroni A, Togias A, Thompson KM, Szefler SJ, Sorkness CA: Randomized trial of omalizumab (anti-IgE) for asthma in inner-city children. N Engl J Med 2011;364:1005-1015

-25 Ivyanskiy I, Sand C, Thomsen SF: Omalizumab for chronic urticaria: a case series and overview of the literature. Case Rep Dermatol 2012;4:19-26. 